www.jmscr.igmpublication.org

Impact Factor (SJIF): 6.379

Index Copernicus Value: 79.54

ISSN (e)-2347-176x ISSN (p) 2455-0450

crossrefDOI: https://dx.doi.org/10.18535/jmscr/v6i11.59

Journal Of Medical Science And Clinical Research

IGM Publication

An Official Publication of IGM Publication

\title{
Association of Aortic Knob Calcification with Intracranial Stenosis in Ischemic Stroke Patients in Tertiary Care Centre
}

\author{
Authors \\ Raju Vijai Usha Raj ${ }^{1}$, Arun Prabu $P^{2}$, Palani Kannan ${ }^{3}$ \\ ${ }^{1}$ Assistant Professor of Medicine, Govt. Royapettah hospital, Govt. Kilpauk Medical College, Chennai, India \\ ${ }^{2}$ Assistant Professor, Govt. Thiruvannamalai Medical College, India \\ ${ }^{3}$ Resident, Govt. Kilpauk Medical College, Chennai, India \\ Corresponding Author
}

Arun Prabu P

Assistant Professor of Medicine, Govt. Thiruvannamalai Medical College, India

Email: p.arunprabu@yahoo.in, Tel: 8825966223

\begin{abstract}
Background: In the arterial bed, Deposition of calcium may indicate the extent of atherosclerotic lesions and aortic knob calcification (AC) is associated with increased risks of cardiovascular and cerebrovascular events. In this study, we evaluated the aortic knob calcification and its clinical importance in ischemic stroke patients with intracranial stenosis and without intracranial stenosis by using simple, non-invasive routine chest radiography.

Aim: To find the prevalence of Aortic Knob Calcification in Ischemic stroke patients with Intracranial Stenosis in Government Royapettah Hospital/Government Kilpauk Medical College. To find the Association of Aortic knob calcification in patients with and without Intracranial stenosis. To evaluate the clinical importance of Aortic knob calcification (AC) in ischemic stroke patients with intracranial (IC) stenosis using simple, non-invasive and routine chest radiography.

Materials and Methods: Patient admitted in medicine department of Government Royapettah Hospital / Kilapuk Medical College. All the cases undergo chest radiography in the posteroanterior (PA) view. The presence of calcification in the aortic knob is recorded. All the cases will undergo MRI Angiography of brain. Based on the findings of the cerebral angiogram, any segment of either intracerebral arteries or extra cranial arteries will be classified as normal, stenosis or occlusion. The classifications will be based on a Radiologist report and the existence of any degree of stenotic lesion will be interpreted as stenosis. Samples will be collected from venous blood after a 12-hour overnight fast, and lipid profiles and standard blood tests will be performed on admission. Here I will compare the proportion of Aortic knob calcification in those with Intracranial stenosis and those without Intracranial Stenosis.

Results: Among the study patients of 102 Aortic knob calcification was present in 32 subjects accounting for 31.4\% .In Aortic Knob Calcification vs ICS, Aortic knob calcification was present in 22 subjects of Intracranial stenosis subjects accounting to 32.4\%. Aortic Knob Calcification-ICS category was analysed using chi-square test, Fisher's Exact Test and pearson chi square, Among the study patients, there was no statistically significant difference.

Conclusion: There was significant association between increased age, Diabetes, Hypertension, Smoking, Alcohol, Aortic Knob calcification and subjects with intracranial stenosis. There was no significant association between Lipid profile Total cholesterol, TGL, HDL, LDL and subjects with Intracranial stenosis.

Keywords: Aortic Knob Calcification, Ischemic stroke, Intracranial Stenosis.
\end{abstract}




\section{Introduction}

In the arterial bed, Deposition of calcium may indicate the extent of atherosclerotic lesions and aortic knob calcification (AC) is associated with increased risks of cardiovascular and cerebrovascular events. ${ }^{11-15}$ As we know Aortic Knob Calcification associated with coronary artery calcification or carotid atherosclerosis, and might have predictive and prognostic value for coronary artery disease. ${ }^{11,16,17}$ Several reports, in addition have shown that aortic knob calcification or aortic atherosclerotic disease is related to ischemic stroke. ${ }^{14,18,19}$ Though its clinical significance for CVA ischemic stroke patients with intracranial (IC) stenosis, one of the major mechanisms of ischemic stroke, remains unclear.

Even though digital subtraction angiograms or thoracic computed tomography (CT) are reliable in detecting aortic calcification, ${ }^{11,20}$ these imaging modalities are not routinely used. In this study, we evaluated the aortic knob calcification and its clinical importance in ischemic stroke patients with intracranial stenosis and without intracranial stenosis by using simple, non-invasive routine chest radiography.

\section{Aim}

1. To find the prevalence of Aortic Knob Calcification in Ischemic stroke patients with Intracranial Stenosis in Government Royapettah Hospital / Government Kilpauk Medical College.

2. To find the Association of Aortic knob calcification in patients with and without Intracranial stenosis.

3. To evaluate the clinical importance of Aortic knob calcification (AC) in ischemic stroke patients with intracranial (IC) stenosis using simple, non-invasive and routine chest radiography

\section{Materials and Methods}

Study setting: Patient admitted in medicine department of Government Royapettah Hospital/Kilapuk Medical College
Ethical Approval: Institutional ethical committee approval was obtained to conduct the study

Study Group: Acute ischemic stroke patients within 7 days of onset, who will be admitted in Medicine department and whom will undergo magnetic resonance angiography at Government Royapettah hospital/ Kilpauk Medical college

Study Design: Cross sectional study.

Population to be studied: 102

Duration of Study: 6 Months (April 2017 September 2017)

Consent: All the patients were given written informed consent

\section{Inclusion Criteria}

$>$ Acute ischemic stroke patients within 7 days of onset

\section{Exclusion Criteria}

$>$ Patients chest X-rays if not properly centered

$>$ Any deviation of the trachea or shift of the mediastinum

$>$ Patients if they had any known disease in the aorta such as aortitis.

$>$ Patients who had cerebrovascular events related to trauma, medical instrumentation, severe concomitant kidney (serum creatinine $\geq 2.0 \mathrm{mg} / \mathrm{dL}$ ) or liver disease

$>$ Patients with autoimmune disease, moyamoya disease, cerebral vaculitis or embolism from implants, such as an artificial heart valves or atrial fibrillation.

\section{Materials to be Used}

$>$ Chest Radiograph Postero- Anterior view

$>$ MRI Angiography Brain

$>$ Blood samples for Total Cholestrol, Triglycerides, HDL, LDL.

\section{Method of Collection of Data}

Sample Size: 102 cases will be studied

\section{Protocol of the Study}

$>$ Acute ischemic stroke patients within 7 days of onset

$>$ For every case selected, detailed clinical history associated comorbid illnesses like 
Diabetes Mellitus, Systemic Hypertension, Hyperlipidemia, Bronchial Asthma, Chronic Kidney disease, Family History of Diabetes Mellitus, Hypertension, geographical area from which patient residing, and results of routine investigations like Complete Blood count, Electrocardiography, X ray chest, Renal function test, Liver Function Test, Urine Routine examination, Blood sugar will be prospectively recorded in the semi-structured proforma. Also In all cases, blood for Fasting Lipid profile will be taken by performing venipuncture and estimation will be done in Clinical Biochemical Laboratory, Biochemical Department at Govt. Royapettah hospital/ Kilapuk Medical College Chennai.

$>$ All the cases undergo chest radiography in the posteroanterior (PA) view. The presence of calcification in the aortic knob is recorded

All the cases will undergo MRI Angiography of brain

$>$ Based on the findings of the cerebral angiogram, any segment of either intracerebral arteries or extra cranial arteries will be classified as normal, stenosis or occlusion.

$>$ The classifications will be based on a Radiologist report and the existence of any degree of stenotic lesion will be interpreted as stenosis

> Samples will be collected from venous blood after a 12-hour overnight fast, and lipid profiles and standard blood tests will be performed on admission.

Here I will compare the proportion of Aortic knob calcification in those with Intracranial stenosis and those without Intracranial Stenosis.

The following investigations were done to all patients included in the study

1.Fasting Lipid Profile

Total cholesterol/Triglycerides/HDL/LDL

2.Renal Function test

Sugar
Urea

Creatinine

Electrolytes

3. Liver function test

Total bilirubin

Direct bilirubin

SGOT

SGPT

Alkaline Phosphatase

Total protein and Albumin

4. Complete blood count including Total count, differential count, ESR

5. Xray chest Posteroanterior view and Electrocardiography.

6. MRI Angiography of brain

\section{Statistics}

The collected data were analysed using IBM.SPSS statistics software 23.0 Version. To describe about the data descriptive statistics, percentage analysis, frequency analysis were used for categorical variables and the mean \& S.D were used for continuous variables. To find the significant difference between the bivariate samples in The Independent groups the Unpaired sample t-test was used. To find the significance in categorical data Chi-Square test was used similarly if the expected cell frequency is less than 5 in $2 \times 2$ tables then the Fisher's Exact was used. In all the above mentioned statistical tools the probability value .05 is considered as significant level.

\section{Results}

We conducted the study for the total number of 102 patients out of which 3 subjects were aged less than 50 years $(2.9 \%), 52$ subjects were $51-60$ years age group $(51 \%), 20$ subject were $61-70$ years age group $(19.6 \%), 27$ subjects belongs to above 70 years $(26.5 \%)$. Predominant number of patients belong to 51-60 years comes to around $51 \%$ of the study.

Next major subgroup belongs to more than 70 years of age. Increased age is associated with Intracranial stenosis of mean age of 63 and without intracranial stenosis subjects of 59 . 
Table 2 showing relation of age group vs Intracranial stenosis in which more number of subjects and presence of Intracranial stenosis is maximum in age group within 51-60 years of age with 41 subjects $(60.3 \%)$, followed by more than 70 year age group with 16 subjects $23.5 \%, 61-70$ years with 11 subjects $16.2 \%$. And Without intracranial stenosis of $8.8 \%$ in subjects upto 50 years of age, $32.4 \%$ in subjects 51-60 years, $26.5 \%$ in subjects $61-70$ years of age and $32.4 \%$ in subjects of above 70 years

Age - ICS category was analysed using chi-square test and pearson chisquare value is 11.363 and degree of freedom is 3 and $p$ value comes around $\mathrm{p}-0.010(\mathrm{p}<0.05)$ which is statistically significant.

Table 1 Age category of the studied population

\begin{tabular}{|l|c|c|c|c|}
\hline & $\begin{array}{c}\text { Frequ } \\
\text { ency }\end{array}$ & Percent & $\begin{array}{c}\text { Valid } \\
\text { Percent }\end{array}$ & $\begin{array}{c}\text { Cumulative } \\
\text { Percent }\end{array}$ \\
\hline Valid Upto & 3 & 2.9 & 2.9 & 2.9 \\
50 yrs & & & & \\
$51-60$ yrs & 52 & 51.0 & 51.0 & 53.9 \\
$61-70$ yrs & 20 & 19.6 & 19.6 & 73.5 \\
Above 70 yrs & 27 & 26.5 & 26.5 & 100.0 \\
Total & 102 & 100.0 & 100.0 & \\
\hline
\end{tabular}

Table 2: Age Range

Age range

\begin{tabular}{|l|c|c|c|c|}
\hline & Frequency & Percent & $\begin{array}{c}\text { Valid } \\
\text { Percent }\end{array}$ & $\begin{array}{c}\text { Cumulative } \\
\text { Percent }\end{array}$ \\
\hline Valid Upto & 3 & 2.9 & 2.9 & 2.9 \\
50 yrs & & & & \\
$51-60$ & 52 & 51.0 & 51.0 & 53.9 \\
yrs & & & & \\
$61-70$ & 20 & 19.6 & 19.6 & 73.5 \\
yrs & & & & \\
Above & 27 & 26.5 & 26.5 & 100.0 \\
70 yrs & 102 & 100.0 & 100.0 & \\
Total & & &
\end{tabular}

This above frequency table reveals that peak incidence of patients with intracranial stenosis is between 51-60 yrs and without intacranial stenosis is above 70 yrs \& 51-60 yrs in my study.
Figure 1: Age range Bar diagram

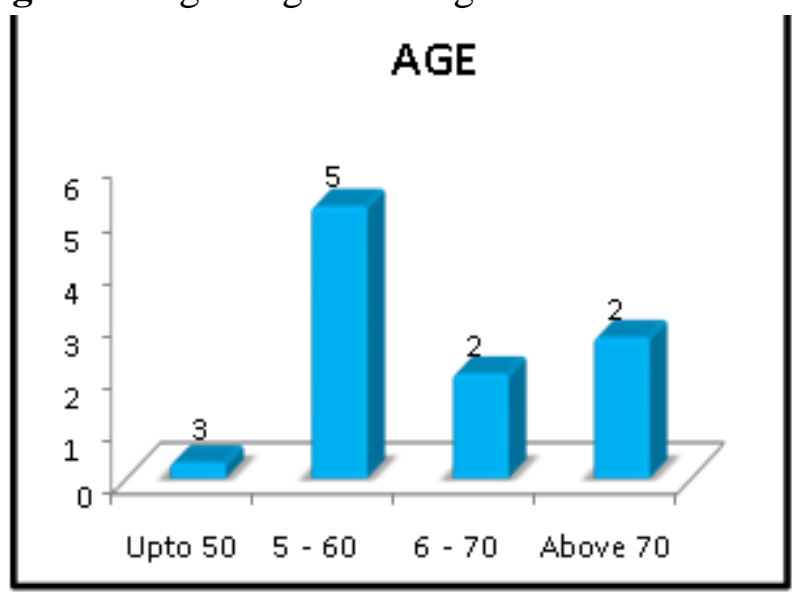

The above Bar diagram shows the age group incidence is more with 51-60 years of 52\%

Figure 2: Mean Age Bar diagram

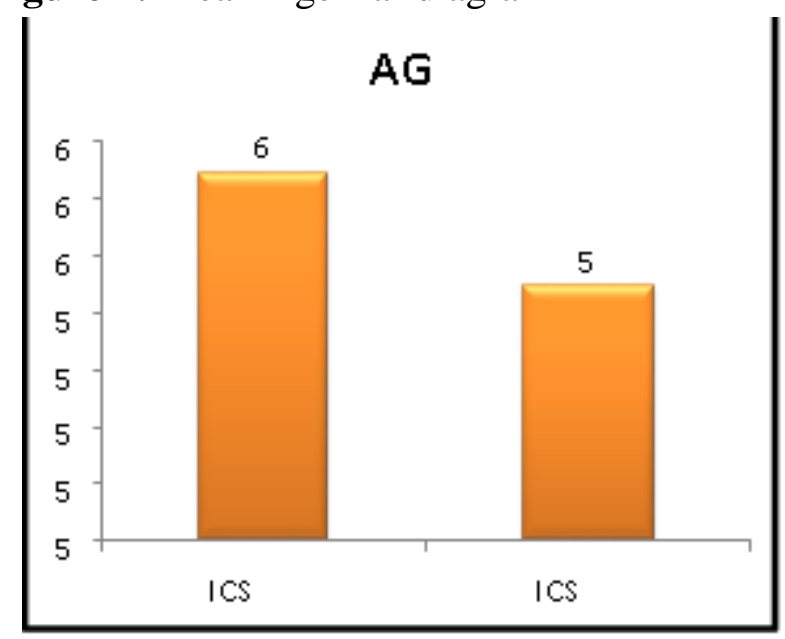

This above bar diagram shows the mean age which is maximum for patients with Intracranial stenosis of 63 .

Figure 3: Age range vs intracranial stenosis Bar diagram

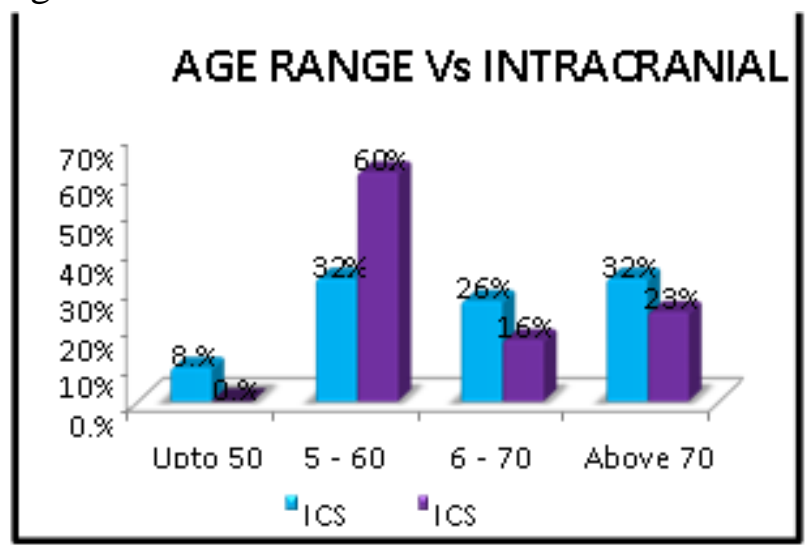


The above Bar diagram shows the incidence of intracranial stenosis in CVA with respect to age group with maximum incidence being between 51-60 yrs.

\section{Sex Distribution}

Among these 102 patients studied, male patients were 58 in number $(56.9 \%)$ of the study and female subjects were $46(43.1 \%$ of the study). Among the study patients, there was no statistically significant difference in relation to gender status majority are males $56.9 \%$.

Table 3: Sex distrubution

\begin{tabular}{|r|c|c|c|c|}
\hline & & & Valid & Cumulative \\
& Frequency & Percent & Percent & Percent \\
\hline Valid Female & 44 & 43.1 & 43.1 & 43.1 \\
Male & 58 & 56.9 & 56.9 & 100.0 \\
Total & 102 & 100.0 & 100.0 & \\
\hline
\end{tabular}

\section{Hypertension}

Among the study patients, hypertension was present in about 49 Subjects of CVA of $48 \%$ and in subjects with ICS, $61.8 \%$ of subjects had hypertension. Hypertension -ICS category was analysed using chi-square test and pearson chisquare value is 15.396 and degree of freedom is 1 and $p$ value comes around $p-0.000(p<0.05)$ which is statistically significant.

Table 4: Frequency of hypertension Hypertension

\begin{tabular}{|c|c|c|c|c|c|}
\hline & & Frequency & Percent & $\begin{array}{l}\text { Valid } \\
\text { Percent }\end{array}$ & $\begin{array}{c}\text { Cumulative } \\
\text { Percent }\end{array}$ \\
\hline \multirow[t]{3}{*}{ Valid } & ABSENT & 53 & 52.0 & 52.0 & 52.0 \\
\hline & PRESENT & 49 & 48.0 & 48.0 & 100.0 \\
\hline & Total & 102 & 100.0 & 100.0 & \\
\hline
\end{tabular}

Figure 4: Bar diagram With Hypertension

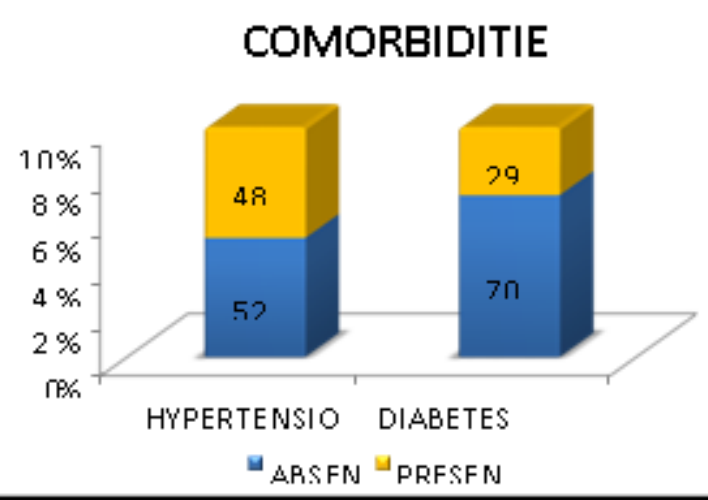

Table 5: Hypertension Vs ICS

\begin{tabular}{|c|c|c|c|c|}
\hline & \multicolumn{2}{|c|}{ ICS } & \multirow[b]{2}{*}{ Total } \\
\hline & & Absent & Present & \\
\hline \multirow[t]{6}{*}{ HYPERTENSION ABSENT } & Count & 27 & 26 & 53 \\
\hline & & $79.4 \%$ & $38.2 \%$ & $52.0 \%$ \\
\hline & $\begin{array}{l}\text { within } \\
\text { ICS }\end{array}$ & & & \\
\hline & Count & 7 & 42 & 49 \\
\hline & & $20.6 \%$ & $61.8 \%$ & $48.0 \%$ \\
\hline & $\begin{array}{l}\text { within } \\
\text { ICS }\end{array}$ & & & \\
\hline \multirow[t]{3}{*}{ Total } & Count & 34 & 68 & 102 \\
\hline & $\%$ & $100.0 \%$ & $100.0 \%$ & $100.0 \%$ \\
\hline & $\begin{array}{l}\text { within } \\
\text { ICS }\end{array}$ & & & \\
\hline
\end{tabular}

\section{Diabetes Mellitus}

Among the study patients of 102, Diabetes was present in 30 subjects in which 28 diabetic patients had intracranial stenosis accounting for 41.2\%. Diabetes -ICS category was analysed using chi-square test, Fisher's Exact Test and pearson chisquare value is $13.600^{\mathrm{a}}$ and degree of freedom is 1 and $\mathrm{p}$ value comes around $\mathrm{p}-0.000$ $(p<0.05)$ which is statistically significant

Table 6: Frequency of Diabetes Mellitus

\begin{tabular}{|c|c|c|c|c|}
\hline & Frequency & Percent & $\begin{array}{c}\text { Valid } \\
\text { Percent }\end{array}$ & $\begin{array}{c}\text { Cumulative } \\
\text { Percent }\end{array}$ \\
\hline Valid ABSENT & 72 & 70.6 & 70.6 & 70.6 \\
PRESENT & 30 & 29.4 & 29.4 & 100.0 \\
Total & 102 & 100.0 & 100.0 & \\
\hline
\end{tabular}

Table 7: Diabetes Mellitus VS ICS

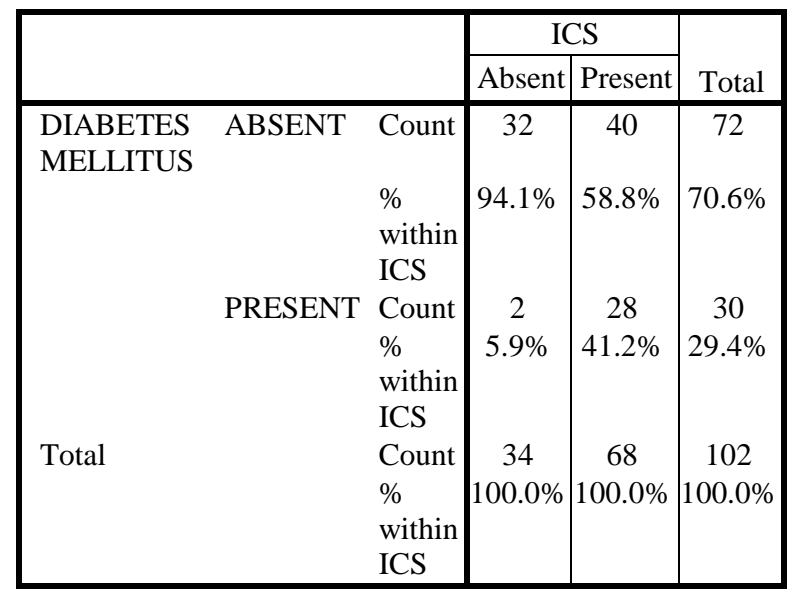

\section{Alcohol}

Among the study patients of 102, Alcohol was being consumed by 31 subjects in which 14 alcohol consumption subjects had intracranial stenosis accounting for $20.6 \%$. 
Alcohol-ICS category was analysed using chisquare test, and pearson chisquare value is $9.269^{\mathrm{a}}$ and degree of freedom is 1 and $\mathrm{p}$ value comes around $\mathrm{p}-0.002(\mathrm{p}<0.05)$ which is statistically significant.

Table 8: Frequency of subjects with Alcoholism

\begin{tabular}{|cl|c|c|c|c|}
\hline & & $\begin{array}{c}\text { Frequenc } \\
\mathrm{y}\end{array}$ & $\begin{array}{c}\text { Percen } \\
\mathrm{t}\end{array}$ & $\begin{array}{c}\text { Valid } \\
\text { Percen } \\
\mathrm{t}\end{array}$ & $\begin{array}{c}\text { Cumulativ } \\
\text { e Percent }\end{array}$ \\
\hline $\begin{array}{c}\text { Vali } \\
\mathrm{d}\end{array}$ & NO & 71 & 69.6 & 69.6 & 69.6 \\
& $\begin{array}{l}\text { YES } \\
\text { Tota } \\
1\end{array}$ & 31 & 30.4 & 30.4 & 100.0 \\
& 102 & 100.0 & 100.0 & \\
\hline
\end{tabular}

Table 9: Alcohol Vs ICS

\begin{tabular}{|c|c|c|c|c|c|}
\hline & \multicolumn{2}{|c|}{ ICS } & \multirow[b]{2}{*}{ Total } \\
\hline & & & Absent & Present & \\
\hline \multirow[t]{15}{*}{ ALCOHOL } & NO & Count & 17 & 54 & 71 \\
\hline & & $\%$ & $50.0 \%$ & $79.4 \%$ & $69.6 \%$ \\
\hline & & wi & & & \\
\hline & & $\mathrm{n}$ & & & \\
\hline & & IC & & & \\
\hline & YES & Count & 17 & 14 & 31 \\
\hline & & $\%$ & $50.0 \%$ & $20.6 \%$ & $30.4 \%$ \\
\hline & & & & & \\
\hline & & $\mathrm{n}$ & & & \\
\hline & & $\begin{array}{c}\text { IC } \\
\text { S }\end{array}$ & & & \\
\hline & & Count & 34 & 68 & 102 \\
\hline & & $\%$ & $100.0 \%$ & $100.0 \%$ & $100.0 \%$ \\
\hline & & $\begin{array}{l}\text { wi } \\
\text { thi }\end{array}$ & & & \\
\hline & & IC & & & \\
\hline & & $\mathrm{S}$ & & & \\
\hline
\end{tabular}

\section{Smoking}

Among the study patients of 102 , Smokers were 34 subjects in which 16 smokers subjects had intracranial stenosis accounting for $23.5 \%$.

Smoking-ICS category was analysed using chisquare test, and pearson chisquare value is $8.824^{\mathrm{a}}$ and degree of freedom is 1 and $\mathrm{p}$ value comes around $\mathrm{p}-0.003(\mathrm{p}<0.05)$ which is statistically significant

Table 10: Frequency of Smokers

\begin{tabular}{|c|c|c|c|c|}
\hline & Frequency & Percent & $\begin{array}{c}\text { Valid } \\
\text { Percent }\end{array}$ & $\begin{array}{c}\text { Cumulative } \\
\text { Percent }\end{array}$ \\
\hline Valid NO & 68 & 66.7 & 66.7 & 66.7 \\
YES & 34 & 33.3 & 33.3 & 100.0 \\
Total & 102 & 100.0 & 100.0 & \\
\hline
\end{tabular}

Table 11: Smoking Vs ICS

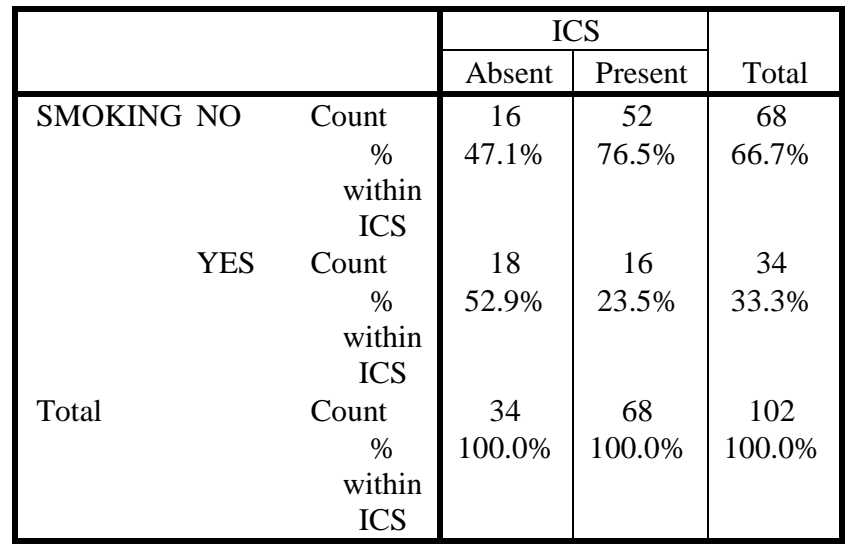

\section{Aortic Knob Calcification}

Among the study patients of 102 Aortic knob calcification was present in 32 subjects accounting for $31.4 \%$.In Aortic Knob Calcification vs ICS, Aortic knob calcification was present in 22 subjects of Intracranial stenosis subjects accounting to $32.4 \%$

Aortic Knob Calcification -ICS category was analysed using chi-square test, Fisher's Exact Test and pearson chi square, Among the study patients, there was no statistically significant difference

Table 13 Shows association and comparison of Aortic knob calcification subjects which was 32 with Intracranial stenosis, in which out of 32 Aortic knob calcification subjects, 22 patient had Intracranial stenosis. Accounting for $69 \%$ association of Aortic Knob calcification with Intra cranial stenosis and $31 \%$ without intracranial stenosis. Hence Subject with Aortic knob Calcification had 69\% significant association of Intracranial stenosis.

Table 12: Frequency of Aortic Knob Calcification

\begin{tabular}{|c|c|c|c|c|}
\hline & & & Valid & Cumulative \\
& Frequency & Percent & Percent & Percent \\
\hline Valid ABSENT & 70 & 68.6 & 68.6 & 68.6 \\
PRESENT & 32 & 31.4 & 31.4 & 100.0 \\
Total & 102 & 100.0 & 100.0 & \\
\hline
\end{tabular}


Figure 5: Bar diagram of Aortic Knob Calcification

\section{AORTIC KNOB}

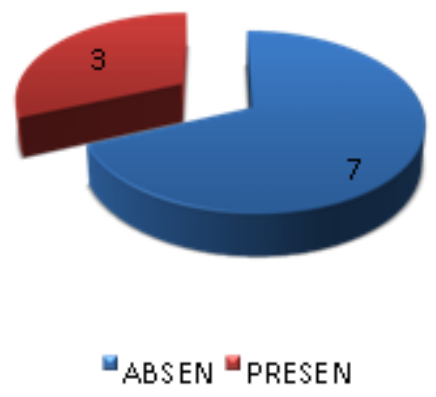

Table 13: Aortic Knob Calcification vs ICS

\begin{tabular}{|c|c|c|c|c|}
\hline & \multicolumn{2}{|c|}{ ICS } & \multirow[b]{2}{*}{ Total } \\
\hline & & Absent & Present & \\
\hline AORTIC KNOB ABSENT & Count & 24 & 46 & 70 \\
\hline \multirow[t]{3}{*}{ CALCIFICATION } & $\begin{array}{c}\% \\
\text { within } \\
\text { ICS }\end{array}$ & $70.6 \%$ & $67.6 \%$ & $68.6 \%$ \\
\hline & Count & 10 & 22 & 32 \\
\hline & $\begin{array}{c}\% \\
\text { within } \\
\text { ICS }\end{array}$ & $29.4 \%$ & $32.4 \%$ & $31.4 \%$ \\
\hline \multirow[t]{2}{*}{ Total } & Count & 34 & 68 & 102 \\
\hline & $\begin{array}{c}\% \\
\text { within } \\
\text { ICS }\end{array}$ & $100.0 \%$ & $100.0 \%$ & $100.0 \%$ \\
\hline
\end{tabular}

\section{Conclusion}

1. In my study patients with intracranial stenosis and without intracranial stenosis were compared and studied

2. There was significant association between increased age and subjects with intracranial stenosis

3. There was significant association between diabetes and subjects with Intracranial stenosis

4. There was significant association between Hypertension and subjects with Intracranial stenosis

5. There was significant association between Smoking and subjects with Intracranial stenosis.

6. There was significant association between Alcohol and subjects with Intracranial stenosis.
7. There was no significant association between Lipid profile Total cholesterol, TGL, HDL, LDL and subjects with Intracranial stenosis.

8. There was significant association between Aortic knob stenosis and Intracranial stenosis when compared to patients without intracranial stenosis of $69 \%$, signifying the importance of simple Chest Radiography in prediction of CVA.

In conclusion, my results suggest that Aortic knob calcification is a reliable predictor for Intra cranial stenosis in ischemic stroke patients. An increase in the use of chest radiography as a screening or risk factor assessment tool may be justified, as AC has a strong specificity for infarcts that may enable a clinician to start medical management on asymptomatic atherosclerosis so as to prevent Cerebrovascular events and also improve the subject outcome; still larger studies are needed in this area as it is first study in our population, to become it generalize.

\section{Acknowledgement}

We the authors sincerely thank the participants, staffs, paramedics and statistician for their cooperation and their contribution towards this study.

\section{Conflict of interest}

All authors contributed equally in developing the manuscript.

\section{References}

1. Gorelick PB, Wong KS, Bae HJ, Pandey DK. Large artery intracranial occlusive disease: a large worldwide burden but a relatively neglected frontier. Stroke. 2008;39:2396-99.

2. Sacco RL, Kargman DE, Gu Q, Zamanillo MC. Race-ethnicity and determinants of intracranial atherosclerotic cerebral infarction. The Northern Manhattan Stroke Study. Stroke 1995;26:14-20. 
3. Qureshi AI, Safdar K, Patel M, Janssen RS, Frankel MR. Stroke in young black patients. Risk factors, subtypes, and prognosis. Stroke. 1995;26:1995-98.

4. Weisberg LA. Clinical characteristics of transient ischemic attacks in black patients. Neurology. 1991;41:1410-14.

5. Wityk RJ, Lehman D, Klag M, Coresh J, Ahn H, Litt B. Race and sex differences in the distribution of cerebral atherosclerosis. Stroke. 1996;27:1974-80.

6. Wong LK. Global burden of intracranial atherosclerosis. Int J Stroke. 2006;1:15859.

7. Kumar G, Kalita J, Kumar B, Bansal V, Jain SK, Misra U. Magnetic resonance angiography findings in patients with ischemic stroke from north India. J Stroke Cerebrovasc Dis. 2010;19:146-52.

8. Moustafa RR, Moneim AA, Salem HH, Shalash AS, Azmy HA. Intracranial stenoocclusive arterial disease and its associations in Egyptian ischemic stroke patients. Stroke. 2013;44:538-41.

9. Feldmann E, Daneault N, Kwan E, et al. Chinese-white differences in the distribution of occlusive cerebrovascular disease. Neurology. 1990;40:1541-45. [PubMed]

10. Gorelick PB, Caplan LR, Langenberg P, et al. Clinical and angiographic comparison of asymptomatic occlusive cerebrovascular disease. Neurology. 1988;38:852-58. 